\title{
GCU
}

Glasgow Caledonian

University

University for the Common Good

\section{Two sides of the same coin: business resilience and community resilience}

\section{Adekola, Josephine; Clelland, David}

Published in:

Journal of Contingencies and Crisis Management

DOI:

10.1111/1468-5973.12275

Publication date:

2020

Document Version

Author accepted manuscript

Link to publication in ResearchOnline

Citation for published version (Harvard):

Adekola, J \& Clelland, D 2020, 'Two sides of the same coin: business resilience and community resilience', Journal of Contingencies and Crisis Management, vol. 28, no. 1, pp. 50-60. https://doi.org/10.1111/14685973.12275

\section{General rights}

Copyright and moral rights for the publications made accessible in the public portal are retained by the authors and/or other copyright owners and it is a condition of accessing publications that users recognise and abide by the legal requirements associated with these rights.

Take down policy

If you believe that this document breaches copyright please view our takedown policy at https://edshare.gcu.ac.uk/id/eprint/5179 for details of how to contact us. 


\title{
Two sides of the same coin: Business resilience and community Resilience
}

$\underline{\text { Adekola, J. and Clelland, D. (2019) Journal of Contingencies and Crisis }}$

Management, (doi:10.1111/1468-5973.12275)

\begin{abstract}
The resilience of small businesses and how that relates to community resilience especially in rural communities has remained an under-researched aspect of community resilience. This exploratory study aims to understand the relationship between business resilience and community resilience in rural communities. Firstly, the research seeks to understand the role that small businesses play in contributing to community resilience activities. The paper then sheds light on enabling and challenging factors that shape how small businesses prepare for and respond to weather related emergencies through the lens of flooding. Data were collected through in-depth semi-structured interviews and surveys with rural small businesses in Scotland. The analysis of the data suggest that businesses play advisory and advocacy roles, make financial and material contributions to local community resilience activities and contribute to quick community recovery through various dimensions of corporate social responsibility activities. However, small businesses face formidable barriers and challenges in preparing for and responding to weather-related emergencies that undermines their own resilience to natural hazards. The paper concludes by suggesting ways in which small businesses can enhance their resilience to natural hazards, while at the same time contributing to community resilience.
\end{abstract}

Key words: Business resilience, community resilience, natural hazards 


\section{Introduction}

The ability for businesses to plan for and respond to the impact of natural hazards within local communities can be fundamental in shaping their responses to those hazards. This is especially important in the United Kingdom (UK) and in particular Scotland, for example, where there is a strong policy focus on empowering local businesses to become 'resilient' to severe weather events (Cabinet Office, 2011; Preparing Scotland Report, 2013). Severe weather events may include heavy rain, heavy snow and extreme heat. A policy focus on empowering local businesses is mainly driven by the belief that the resilience of businesses will have impact for decreasing risk and promoting resilient behaviour in other areas (Preparing Scotland Report, 2013), which ultimately contributes to broader community resilience.

Paton and Johnston (2017) for instance, argue that businesses that have the capacity to recover quickly can continue to provide employment and services in affected areas. Likewise, members of a community that is prepared for emergencies have the tendency to recover faster, and thus, are more likely to be able to support businesses and economic recovery (either as employees or customers) (Paton \& Johnston, 2017). Thus, there is the suggestion that the resilience of businesses and those of local communities are closely linked. However, until now, there is relatively little empirical evidence that sheds light on the relationship between business resilience and community resilience. Existing research has either focused too thinly on the different ways in which the resilience of communities can be understood and measured, or, in business and management studies, on the business resilience and continuity.

The main aim of this study is to understand the relationship between business resilience and community resilience especially in rural communities. In 2016, rural businesses accounted for $30 \%$ of businesses in Scotland, thus contributing significantly to the Scottish local economy (Keane, 2017). Thus, their resilience can help communities become resilient to natural hazards. However, Rosenburg (2017) suggests that the recovery of small businesses from the impact of natural or other hazards can take several years. In fact, according to US Federal Emergency Management Agency (FEMA), 40\% of small businesses never reopen following a disaster, largely because they are not prepared for such emergencies (Morris, 2017) and due to other reasons such as downtime costs, damaged reputation and, critically, lost customers (Willis, 2016). 
The paper begins by critically examining existing research on business resilience and community resilience. This is important if new research is to contribute to filling potential gaps in existing scientific literature. By means of a primary research, the paper illustrates how small businesses in rural communities contribute to the resilience of local communities to weather related emergencies. The paper further examines the experiences of local business as it relates to their preparation and response to a previous flood event. The study concludes by shedding light on the relationship between business and community resilience and sets out potential areas for further research.

\section{Existing literature on business resilience and community resilience}

The increasing use of resilience across a number of different contexts has itself been subject to critique in the academic literature. At the conceptual level, it has been described as fragmented and under-theorised (Pike, Dawley, \& Tomaney, 2010) and as a 'fashionable concept' that should be carefully scrutinised to assess its value in being applied to different fields (Hassink, 2010). The transmission of resilience as a concept from the natural to the social sciences can also be seen as problematic, with tension between a somewhat conservative notion of the ability to 'bounce back' following some external shock and a more dynamic understanding based around adaptive capacity and more profound change (Brown, 2014; MacKinnon \& Derickson, 2013; Steiner \& Atterton, 2014). However, for the purpose of this study, we subscribe to the UK government framing of community resilience as the ability of communities to "use local resources and knowledge to help themselves during an emergency in a way that complements the local emergency services" (UK cabinet office, 2014).

While the literature shows a variety of approaches that seek to explore the concept of resilience in relation to business, the majority of work around community resilience with regard to natural hazards has tended to focus on the preparation and response undertaken by government and public sector agencies or community groups, with little attention paid to the role of firms (McKnight \& Linnenluecke, 2016) despite their strategic importance within communities (Hallett, 2013). Where research has addressed the private sector in this context (often based on examples from the USA) this has largely been concerned with the 
contribution of large firms to disaster response and recovery either in the form of corporate philanthropy, perhaps driven by notions of corporate social responsibility, see for example (Besser \& Jarnagin, 2010; Tilcsik \& Marquis, 2013), or in commercial activities where revenue is generated from the provision of disaster-related goods and services. McKnight and Linnenluecke (2016) seek to distinguish here between firm- and community-centric 'postures' on the part of business, where the former implies a set of responses prioritising business needs, while the latter takes into account the broader advantages of engagement with community stakeholders, whether based on instrumental aims such as reputational benefits or some sense of moral or compassionate duty. The role of private sector firms as owners and operators of critical infrastructure is also a growing area of interest (see for example (Stewart, Kolluru, \& Smith, 2009).

Literature on community resilience as it relates to the role of small businesses can be broadly separated into two themes. Firstly, researchers in entrepreneurship and management have examined the resilience of small businesses themselves in the face of natural hazards or other crises, see for example (Doern, 2016; Wedawatta \& Ingirige, 2012), often through the lens of business continuity. This work has focused on the experiences and responses of owners and managers to crises and has sought to identify factors that influence the ability of businesses to survive and to maintain revenue streams and employment. In common with communities, preparedness or readiness is seen as one of the key determinants of resilience (Orhan, 2016) for businesses. Most existing research does however tend to focus on larger organisations rather than SMEs (Herbane, 2010; Sullivan-Taylor \& Branicki, 2011).

Orhan (2016), in an extensive review of the research into business preparedness, notes a range of influencing variables - including business size, sector and age, financial situation, occupancy tenure, market range and previous disaster experience (see also Atkinson, 2013; Hallett, 2013). Furthermore, there is evidence that firms are only likely to engage in preparedness activities when they find these easy and when they do not require substantial investment (Tierney \& Webb, 2001). Small and Medium Enterprises (SMEs) in particular, are more likely to be vulnerable (UNDP, 2013), be under-insured and less likely to have contingency plans. In addition to the 'internal' characteristics of businesses and their owners, the capacities and responses of the wider community, including the state, are identified as contributory factors (Doern, 2016). 
Secondly, a distinct strand of research has explored the role played by small business in the resilience of places or communities. This work has tended to focus on resilience to economic shocks or longer-term changes (such as ageing populations) as opposed to natural hazards or emergency situations. (Steiner \& Atterton, 2014), stressing the links between economic and social resilience, note the importance of diverse employment opportunities and private sector enterprises' adaptive capacity in contributing to rural areas' wider resilience. In a similar vein, Maybery, Pope, Hodgins, Hitchenor, and Shepherd (2009) (building on work by Mowbray et al.,2007), present a model of community resilience based on local strengths and resources. While including social assets that develop relationships and shared values - with a clear link to the concept of social capital (Aldritch and Mayer, 2015) - this model also includes economic resources such as employment opportunities, income and certain services. A focus on small business also suggests a potential link to the importance of local ownership of assets as a contributor to rural resilience (Leach, 2013), mostly with regard to land and natural resources (see for example (Skerratt, 2013; Varghese, Krogman, Beckley, \& Nadeau, 2006).

However, there are also clear links here to the broader socio-economic characteristics of places and their populations as the context within which community resilience to emergencies exists. The work of a number of authors (see for example Colten, Kates, \& Laska, 2008; Cutter, Boruff, \& Shirley, 2003; Norris, Stevens, Pfefferbaum, Wyche, \& Pfefferbaum, 2008) has highlighted the role of social inequalities, unemployment and low income as a key source of vulnerability and lack of resilience. A. Kazmierczak, G. Cavan, A. Connelly, and S. Lindley (2015) also added that the indirect impact on the employment provided by those businesses affected by natural hazards is a potentially important aspect of places' social vulnerability, with particular relevance to casual workers or low-income groups. This also relates to issues of disaster recovery, where the ability of businesses to continue operating and employing people is an important element of community recovery (Kapucu \& Sadiq, 2016). As Orhan (2016) argues, as "businesses play a crucial role in the development of a community, their response capacity is essential to enhancing community resilience" (p47).

Having considered existing research on business and community resilience, there is evidence to suggest that there is a gap in and a lack of empirical evidence that sheds light on the understanding of the links between business resilience and community resilience in preparing for and responding to emergences especially in rural communities. Business in rural 
communities are often SMEs, typically characterized by lower levels of skills and qualifications in the workforce, small financial resources and small customer base (Lekhanya, 2011). The vulnerability of small businesses means that the livelihood of many who rely on this sector (mainly agricultural) in rural communities are at risk from the impacts of natural hazards

\section{Research Method and Methodology}

\subsection{Research Aims}

In order to address the identified gap in literature, the aim of this research as reflected in the research questions are:

1. What is the role of small businesses in contributing to local community's resilience activities as it relates to weather related emergencies? and

2. What can we learn from the experiences of small businesses in planning for and responding to weather related disruptions in rural communities?

Several key themes are of interest to this research and are highlighted in Table 1. Within this, we sought to understand how personal, governance and institutional factors could either act as enablers or barrier to engagement and contributions to community resilience and to businesses preparing for and responding to flooding.

\section{Table 1: Research themes}

\begin{tabular}{|r|r|}
\hline Research Themes \\
\hline 1. & Perception of resilience from the business owners/mangers perspective \\
\hline 2. The role of small businesses to community resilience activities & Businesses engagement and contributions to community \\
& resilience \\
& Motivations for business engagement and contributions \\
& Barriers and challenges to business engagement and \\
& contributions \\
\hline 3. Flooding experiences of small businesses to flooding & Knowledge of rights and responsibilities
\end{tabular}


Impact of flooding including emotional feelings

Barriers and challenges in preparing for and responding to flooding

\subsection{Participant recruitment and data analysis}

The research was conducted in two stages, both of which were approved following reviews by the College of Social Sciences Research Ethics Committee of University of Glasgow. The first stage of the research sought to understand the role of small businesses in contributing to the resilience of community resilience activities. In the first stage of research, participant was asked questions around their perception of resilience, their contribution and engagement with community resilience, their motivations for engagement. Telephone interviews were conducted with 4 small business owners or managers who had been involved in some way in how their local community planned for or responded to emergencies. The interviewees represented locally owned and managed businesses in three largely rural local authority areas - the Scottish Borders, Argyll and Bute and Perth and Kinross. The businesses were a partnership of two part-time owner-operators providing specialist technical services; a retail business with 30 employees; a local service provider with 4 employees; and a landowner engaged in a variety of activities including agriculture, tourism and energy generation, with around 80 employees. Each of the communities where these businesses were located had a community resilience plan in place. These places had experienced a variety of extreme weather events, including widespread fluvial flooding in 2015 that required around 600 residents to be evacuated in one location, and significant storm damage and power outages in 2012 .

In the second stage of the research with a different set of business owners and managers, participants were asked to reflect on their previous experiences of flooding within the last three years and their current engagement with resilience groups and activities. Participants were asked questions around enablers, challenges and barriers that small business face in planning and responding to reduce the impact of natural hazards. Data was collected from 12 participants using face to face interviews and surveys. In total, 16 business owners and managers participated in the two studies. All the businesses surveyed in the second part of the research were also locally owned and managed and based in Newton Stewart in the Dumfries 
and Galloway local authority and operate in business such as restaurants, second cloths, books and barbing saloons. In Newton Stewart, there are frequent flooding events from River Cree which runs by the main business district of the community where most of the businesses surveyed in operates, with flooding events in 2012, 2013 and 2016 (Adekola 2018).

Potential participants were identified through consultation with resilience and emergency planning officers in local authorities and members of local community councils and other resilience groups. This therefore represented a type of purposive sampling (Palys, 2008). Interviews were conducted during March and August 2017. Semi-structured interviews and surveys were utilised on the basis that participants could be asked specific questions about their experiences, motivations and perceptions, but the process allowed sufficient flexibility for participants to raise issues of particular interest to them and for follow-up questions to probe on particular points (Bryman, 2015). Participants were asked for some basic background information about their business, and to recount their experiences of involvement in community resilience activities. The data were analysed using thematic analysis (Clarke \& Braun, 2014) also informed by extant literature.

All the four local authorities were these businesses are located are rural communities in Scotland. These communities are typically dispersed, far from large settlements. In common with many rural and peripheral areas, these places face social and economic challenges related to older than average resident populations, high levels of self-employment, few large businesses and an economy that is disproportionately reliant on agriculture, tourism, and local retail and services (Davies and Michie, 2011).

\section{Policy Context}

The report 'Preparing Scotland, Scottish Guidance on Resilience, (2013)', defines community resilience as "communities and individuals harnessing resources and expertise to help themselves prepare for, respond to, and recover from emergencies, in a way that complements the work of the emergency responders" (Community Resilience Guidance, 2013 p.1). This definition emphasises the culture of preparedness amongst vulnerable population, who are to take responsibility to prepare for, respond to, and recover from emergencies. It recognises capacity building of individuals and communities wherein, during emergencies assets (e.g. resources, skills and network) can be utilised as early and as 
effectively as possible before emergency help arrives. In this context, resilience is seen as “everyone's business" (Preparing Scotland, 2016 p.1). For this reason, Scotland operate a multi-agency approach to community resilience involving both category one and category two responders. Category one responders include public institutions such as the police, local authorities, NHS Health Boards, ambulance, fire and rescue services, the Maritime and Coastguard Agency, ambulance, fire and rescue services, local authorities, NHS Health Boards, the Scottish Environment Protection Agency. Category two responders with lesser responsibility include rail and air transport operators, NHS National Services Scotland, gas and electricity companies, Scottish Water, telecommunications providers and harbour authorities (Preparing Scotland, 2016 p.1).

Given the reality of emergencies, individuals, businesses and communities also bear the burden for their own safety and resilience. In some of the communities we surveyed, informally organised community groups and members of local community councils take up responsibility for community resilience on a voluntary basis. Before and during emergencies, the Government working in partnership with local responders play a central role in providing safety and resilience information to the public and are placed to do so in emergencies through the establishment of public communication groups (PCG) (Scottish Government, 2008) as the public look to these institutions for relevant information (Adekola et al, forthcoming). The PCG consist of communication practitioners brought together under the multi-agency Strategic Co-ordination Group (SCG). The PCG must be activated during emergencies especially where co-ordinated communication is required.

\section{Results}

\subsection{Perceptions of Resilience from the business owner's/managers perspective}

All interviewees explicitly associated the concept of community 'resilience' with the specific arrangements in place to respond to natural hazards or other emergencies.

\footnotetext{
"Resilience to me is what happens when things go wrong or what happen when the unexpected happens and how well you are able to cope with it. So it is contingency planning, and putting in place resource or back-up in the event of the unexpected"
} 
"Resilience to me means supporting the people who have been in a crisis position to re-establish them and become resilient to what goes on round about them"

This is likely to have been influenced by the framing of the interviews, primarily focused on businesses engagement with these arrangements, and to reflect the common use of the term in the context of community resilience groups and planning that they had been involved in. Respondents talked in terms of 'safeguards', 'preparedness' and 'the unexpected', as well as post-event recovery. This was also linked by one respondent to measures taken within their own business.

\subsection{The role of small businesses in developing the resilience of communities to natural hazards}

i. Engagement and Contributions

Participants were engaged in community resilience arrangements and responses in different (and sometimes multiple) ways. These includes as - members of local community resilience group, members of the local flood group (i.e. a constituted group outside the local authority's community resilience planning framework and through providing support to police as part of a missing person's incident; and being registered on the list of volunteers and assets as part of their local Community Resilience Plan.

"The business contributes, for instance the database for the people that are vulnerable. That is run through my computer; any extraordinary expenses are run through the system ... My staff supports me in some of the things that I do as well ... My company put in quite a high value monetary sum to support us as a group”

We helped with machinery to initially try and avert the flood but then when the flood came we ... helped, with the emergency services, to get affected parties out of their properties.

Others are financial contributions to local groups, in-kind contributions to local groups - such as stationery, postage, and hosting a database of vulnerable persons, using business premises to store equipment (e.g. sandbags) and providing employee time and machinery to deploy and 
remove flood prevention measures, to help vulnerable people to shelter, to clean up following natural hazards, etc. These are summarised in Table 2.

Table 2: Businesses engagement and contributions in preparation for and in response to emergencies.

Businesses engagement and contributions

Volunteering of time and effort.

* Contributions in kind including the provision of machinery, stationery and hosting a database of vulnerable persons.

* Sheltering affected people and their properties in emergencies

Assist with clean up after emergencies

\section{ii. Motivations}

All interviewees talked about their involvement in terms of being 'civically minded', 'neighbourly', having a 'responsibility' to the community or of 'giving something back'. Those in the most rural areas explicitly linked this to the particular circumstances and culture of these places, both in terms of the perceived higher levels of interaction and cohesion between members of the community - pointing towards notions of social capital - and the sense that they were more remote from services and statutory responders such as police, fire service or local authorities.

"There is a sense of community here"

"When you work in rural remote areas you have to be more self-reliant"

In one case the interviewee explicitly linked their involvement in their local resilience group to their local ownership and a sense of historic 'connectivity' to the community, feeling that this motivation would not exist to the same extent if they were owned or managed from elsewhere. For two of the businesses, their involvement in their local community resilience group was a direct result of their own premises being directly affected by flooding in the past. In these cases, some degree of self-interest, an understanding of the consequences of flooding and empathy with others affected were motivations. However, interviewees were also aware of how their businesses were perceived in their communities, the ways in which their participation in community resilience activities might affect this, and how this might be of longer term benefit to them: 
"Maybe if people see me helping the actual town they will think I am a good guy and giving something back to the community and may use my [business]",

This was also linked explicitly by the representative of the largest employer to the concept of corporate social responsibility (CSR):

"Community resilience needs to come into the CSR basket of things that get reflected well and get good $P R$ and good recognition"

Overall therefore, these businesses can be seen as adopting combinations of both firm- and community-centric postures (McKnight \& Linnenluecke, 2016). There was also an element of personal satisfaction, self-esteem and enjoyment that some individuals derived from their involvement, both in terms of making a contribution to their community and of the social aspects:

"I want something more fulfilling and credible ... I would like to be seen as being able to offer something of a more useful nature"

"We are a tight band and we come out, we do what we need to do. We have good banter about it and then go home"

These responses point towards the potential applicability of research on the motivations of individual volunteers more generally (See Table 3).

Table 3: Motivations for businesses engagement and contributions in preparation for and in response to emergencies.

Motivations for businesses engagement and contributions

* Personal reasons including sense of fulfilment and reliance

* CSR - corporate social responsibilities

* Collective responsibility

* Business safeguarding reasons 
iii. Barriers to engagement and contribution

As the interviewees had all been identified on the basis of their participation in planning or responding to incidents, they were not necessarily well placed to identify barriers to participation. Nevertheless, there were several issues highlighted as perceived to be preventing or restricting the contribution of businesses to this type of activity. Two of the interviewees explicitly identified other businesses in their localities as not making a contribution to community resilience efforts beyond safeguarding their own property. While this was described by one respondent as 'selfishness', whether they should necessarily be expected to 'carry the burden' of activity that in the past might have been seen as the responsibility of local authorities was also questioned, although interviewees were also aware of the impact of cuts to public sector spending. Related to this, the planned increase in business rates was highlighted in one case as both putting additional pressure on small businesses and potentially damaging the willingness of businesses to engage in voluntary schemes:

"Playing devil's advocate, it is the council's responsibility to look after us. We are already paying them money to do that."

In addition, it was also noted that in rural areas and small towns many businesses were very small or 'one man bands', and owner/managers could therefore struggle to take time away from their business to commit to volunteering.

Aside these economic reasons, governance and institutional issues were also raised as having potential to act as barriers to the effective engagement of businesses in community planning and response. This was manifested in several ways. One of the interviewed businesses providers of a specialised service using high technology equipment - were keen to offer their services but had faced specific practical barriers around the issue of whether equipment deployed in an emergency situation would be covered by insurance - leaving the owners at risk of a substantial financial loss. Related to this, the 'asset register' system used by community resilience groups was felt to be primarily a register of individual local volunteers without the scope for business assets. The support provided by local authority officers was seen as important in facilitating and supporting the development of effective community resilience arrangements. However, given the impacts on local authorities of cuts to public sector spending, the time and capacity of staff to effectively support community 
organisations, and to help them engage local businesses, was seen by one interviewee as limited. The existence in one case of both a well-established locally constituted flood group and community council led resilience group (as part of the local authority's community resilience planning framework) led to some tension with the latter seen by interviewees as less effective. Concern over the developing formalisation of community resilience planning was expressed by one respondent, seeing this as a risk to the willingness of businesses to donate time and equipment on a more informal basis. These barriers to businesses engagement and contributions are captured on Table 4.

Table 4: Barriers to businesses engagement and contributions in preparation for and in response to emergencies.

Barriers to businesses engagement and contributions

* Perceptual issues such as 'not my responsibility'.

* Economic reasons including cost with regards to time, effort and business disruptions.

* Knowledge on safeguards.

* Governance and institutional factors

○ Insurance arrangement

○ Tensions between different groups

- Embedded error cost in processes for example around asset register.

\subsection{Experience of business owners and business in planning and responding to} reduce the impact of natural hazards

i. Knowledge of rights and responsibilities

Not all respondents knew what their rights to managing extreme events are but there was a general sense of responsibility to reduce or minimize potential impact as much as possible.

"Be aware of the effect of what is going on [...] the environment. Don't try and cut down on thing and as far as protecting the business"

There were those who never really thought about having a responsibility in mitigating flooding (before the flooding happened) because they had never experienced it. 


\section{ii. Impact of flooding}

In terms of the impact of the flooding, participants identified a range of issues in the immediate and long-term impacts following the flooding. In the immediate terms, there were accounts of loss of business stock due to power outage and contamination from floodwaters, loss of trade ranging between 10 days and 9 months. There were shops that never reopened after the flooding. In the longer term, responses pointed to rise in insurance cost and loss of customer base.

"We used to get a lot of holiday makers but since the flooding we don't get holiday makers anymore. Essential goods shops are still ok but a lot of shops like clothes are struggling",

This suggests that for some small businesses, business continuity could potentially remain a myth and not practicable in some instances especially where their customers base is unable to access services and trade that they offered due to road closures or relocations. Some recounted psychological impact such as physical stress and emotional distress.

"It was shocking and very emotional although worse things happen in the world"

Participants were asked to describe their feeling after they had experienced flooding. Responses ranged from feeling of "shock", "devastation", "numbness", and "annoyance”. One respondent mentioned she felt so alone despite the fact that others within the community suffered the flooding.

"I felt desperate and the time is so short you don't know where to turn. I felt dreadfully alone like I was the only person it happened to despite it happening to the whole town"

According to her, there was a lot of community support including offer of food and clothing but the emotional support she needed was not available.

"There was offer of food or clothing or something like that and I am thinking it wasn't suitable for what I was needing really...talking about it with a group of people makes you feel better, it's therapeutic"

This suggests that there may be a need for person-centred approach (Rogers, 1981) in providing support in the immediate aftermath of a disruptive event. 
iii. Enablers, Barriers and Challenges

Respondents were asked to reflect on the event and identify what helped them to prepare for and recover from the flooding. Before the flooding event, none of the six business respondents interviewed had taken any steps to reduce their exposure to flooding, apart from having flood insurance. This inaction was linked to a number of factors including unawareness of the potential of flooding in the area, lack of early warning, no clear understanding of what action to take to protect themselves and lack of clarity about who is responsible for what. In the aftermath of the flooding, respondent linked their ability to quickly recover to water resistant floors, community spirit - help from family, friends and member of the community

"Marble floor helped. No carpet to dry out"

"Community worked well together"

"I spent time with my husband cleaning my shop, it was therapeutic ...it's helped me out of depression"

Respondents were also asked to identify what factors stopped them from taking mitigating action before and after the flooding and to recount any bad experience encountered after the flooding. Responses suggest a lack of awareness of how to protect properties, knock on effect on electricity with cascading consequences, loss of customer in the aftermath of flooding and insurance cover problems.

"The biggest difficulty was the knock on effect on electricity..."

"[After the flooding] the insurance went up three fold... because I made a claim. We had fill insurance, but after the flooding we could afford to pay it. The best offer was $£ 500.00$ and we couldn't afford to pay it... for partial insurance”

People are not coming into the town after the flooding because so many shops were closed"

Table 5: Enablers, Barriers and Challenges in preparation for and response to emergencies. 


\begin{tabular}{|l|l|}
\hline Enablers & Barriers and Challenges \\
\hline Physical design of premises & Loss of customers \\
$*$ Community cohesion & Disruptions to infrastructure \\
& accessible Social capital \\
& an event. \\
\hline
\end{tabular}

\section{Discussion}

Understanding the role that small business play in contributing to the resilience of local communities to natural hazards is fundamental step in understanding the relationship between business resilience and community resilience. The data collected in this study suggest that small businesses in rural communities actively contribute to community resilience activities by acting in advisors or advocacy roles, providing small financial or material donations to local resilience activities, and directly contributing to volunteering groups in order to deal with the immediate aftermath of the crisis. The analysis of the data suggest that some small business owners or managers are members of local resilience groups, and they advocate and seek solutions appropriate to their needs (e.g. business insurance/reduction schemes) in resilience planning, use business premises as information centres, provide employment for members of the community and financial aid for local community activities.

The data also suggest that small business owners or managers tend to act as volunteers in an individual capacity, contributing relief materials, use business premises as congregation venue in the immediate aftermath of an event and join in the community clean up in the aftermath of flooding. The contribution and motivation of business owners is therefore comparable with those of volunteers more generally, on which there is existing research (Woolvin \& Rutherford, 2013). The contribution of small businesses to community resilience activities is important as rural communities are often at more distance from services and statutory responders such as police, fire service or local authorities. Thus, they contribute to the social capital of local communities identified in extant literature as critical to been resilient to natural hazards (Aldrich \& Meyer, 2015).

The results further illustrate how businesses plan (or not) for emergencies. A number of 
factors were found to enable small businesses take protective steps to reduce their vulnerability to potential harm. This includes awareness of probability of hazards and what protective steps to take, the physical location and configuration of the property and the help of families and friends (social capital). However, there are a number of challenges and barriers small businesses encounter that act as barriers in their ability to prepare for and respond to potential harm from natural hazards. Data in this study suggest that key areas of concern for small businesses as it relates to their resilience to natural hazards centers on the potential loss of a customer base with consequences for cash flow, the impact on electricity and how that is linked to their ability to trade, and difficulty around insurance cover in the aftermath of the flooding, most likely to affect SMEs (Crichton, 2006). However, what is most important is the ability for business owners and managers to strategically think about their vulnerabilities, and how they plan to reduce their threats from it.

One interesting insight that can be drawn the results is that they highlight important resilience indicators for businesses in preparation for, and in response to emergencies such as natural hazards (see Tables 4 and 5) in a way aligns with Cutter et al's (2010) community resilience indicators/framework. Cutter et al (2010), for example, identifies 49 indicators of community resilience that are grouped to five categories: social, economic, institutional, infrastructure, and community competence. The social resilience capture demographics characteristic of community including their physical and mental wellness and level of communication and mobility. Economic resilience relates to issues income and employment, housing, diversity, and equality. Institutional resilience covers issues around mitigation strategy, risk transfer mechanisms and policy protections. The quality of housing construction and physical capacity of infrastructure are included infrastructural resilience. Community competence captures issues the good will of local citizens through community engagement and involvement.

Table 6: Integrating insight from Results with Cutter et al (2010) community resilience framework.

\begin{tabular}{|l|l|}
\hline Community resilience & Research Results (from Table 4 and Table 5) \\
dimensions (Cutter et & \\
al 2010) &
\end{tabular}




\begin{tabular}{|c|c|}
\hline Social & $\begin{array}{l}\text { - Community cohesion } \\
* \text { Accessible Social capital }\end{array}$ \\
\hline Economic & $\begin{array}{l}\text { Economic reasons including cost with regards to time, } \\
\text { effort and business disruptions. } \\
\text { Loss of customers } \\
\text { - Cost of insurance in the aftermath of an event. }\end{array}$ \\
\hline Institutional & $\begin{array}{l}\text { * Governance and institutional factors } \\
\circ \text { Insurance arrangement } \\
\circ \text { Tensions between different groups } \\
\circ \text { Embedded error cost in processes for example } \\
\quad \text { around asset register. }\end{array}$ \\
\hline Infrastructure & $\begin{array}{l}\text { Disruptions to infrastructure } \\
\text { * Physical design of premises }\end{array}$ \\
\hline $\begin{array}{l}\text { Community } \\
\text { competence }\end{array}$ & Knowledge of safeguards. \\
\hline- & * Perceptual issues such as 'not my responsibility'. \\
\hline
\end{tabular}

Table 6 attempts to integrate insight from Table 4 and 5 with Cutter et al (2010) community resilience framework. We find that enablers to enhancing business responses to emergencies such as community cohesion and accessible social capital relates to the social dimension. Cost associated with volunteering in terms of time, effort and business disruptions; loss of customer and insurance cost relates to economic dimension. Constrains brought about by insurance arrangement, tensions between different groups and embedded error cost in processes are seen to relates to governance and institutional factors. Disruptions to infrastructure and physical design of premises can be related to infrastructure and knowledge of how to protect one self and to keep safe can be said to relate to community competence. However, Cutter et al (2010) community resilience framework did not account for personal factors such perceptual issues that enhance or inhibit resilience. This perhaps can be explained by the fact that framework emphasis "community" as a group of people. Future research could potentially look at how personal and individual factors contributes to 
community resilience. Such a research could identify if there is the scope to include individual factors as dimension with in community resilience framework such as those of Cutter et al (2010). Future research should also consider explicating how groups such as businesses contribute to community resilience more explicitly.

If, as is suggested here, small businesses in rural communities play a potentially significant role in local community resilience activities, and considering the barriers and challenges they face in preparing and recovering from natural hazards, there may be a need for holistic approaches that involve a wider range of stakeholders to take a positive step in order to promote the resilience of small businesses and ultimately community resilience. Firstly, businesses need have access to relevant weather-related information and risk assessment information better decisions for their business in the face of risk and uncertainty. There is the potential here for public agencies and organization to help small businesses through information sharing, technical and training assistance to build the necessary skills needed to take resilient steps.

Secondly, small businesses have a role in ensuring that they provide products and services to meet consumer demand in a changing climate. Finding and offering products and services that help consumers build resilience, plus finding ways to better access new markets in a changing customer demand climate, can greatly help small businesses become more resilient and prosperous. Adapting an organizations business objectives may be required in a fast and changing climate following a disruption to ensure business continuity even if this means adapting the products and services offered. However, this will come with its own challenges depending on the nature of business, the liquidity of assets and available resources (in terms of time, expertise and infrastructure) to do so. Small businesses could also seek to partner with other businesses or public entities to enable them have access to a pool of resources and funding and to self-insure against weather-related shocks.

Finally, one major challenge small businesses face in to taking protective steps is the lack of available financing options to invest in their resilience to natural hazards. However, more options are becoming available to provide low-risk financial instruments to support small businesses resilience investment, including disaster reduction schemes insurance, loans and seed capital. 


\section{Conclusions and Further Research}

There is a large and diverse literature across a number of fields concerned with the concept of 'resilience'. This includes research looking at different ways in which the resilience of communities can be understood and measured, and a body of work in business and management studies concerned with the business resilience and continuity. There is however relatively little research looking at the role of businesses (and in particular SMEs) in the communities' efforts to plan for and respond to the impact of natural hazards. This study represents an attempt to explore this area with a focus on identifying issues for further research. Due to the small number of participants in this study, this cannot be considered as comprehensive audit and should instead be considered as an exploratory or pilot study.

Beyond this, the data collected here can help to contribute to a framework for future research in this area. This research has concentrated on the perspectives of business owners and managers, although the relatively small sample size limits the conclusions that can be drawn from this work. There is therefore potential for a much more substantial research project that gathers data from businesses. A more holistic 'case study' approach that focuses on places that have been affected by natural hazards and/or have active community resilience groups or plans may be more fruitful. This would take account of the dual role of businesses as potential contributors to resilience while also dependent to some extent on the broader resilience of their community, with links to recent work on the broader resilience of systems and networks, and the complex inter-connections between organisations and groups, see (Kent \& Fazey, 2015). There would also be benefit to carrying out research with other stakeholders - in particular community groups, local authorities and other responders - about how they engage with businesses and the value that is placed on business contributions.

In particular, several broad areas emerge for further investigation. Firstly, there are governance and institutional factors and in particular the extent to which approaches to community resilience in different places consider or attempt to integrate businesses into planning structures and responses. This is important as findings from this exploratory study seems to suggest that governance and institutional factors are important issues in shaping businesses engagement and contribution to community resilience activities. This links to issues of how 'the community' in this context is represented and differences in local capacity. 
Secondly, there is the need to understand the influence of local ownership and other business characteristics, for example, whether businesses that are locally owned and managed are more likely to engage in community resilience activities. This would raise questions about whether and how business units with less local autonomy (e.g. chains, franchises, branches of larger firms) can be engaged in supporting community resilience, perhaps with reference to ideas of corporate social responsibility. Businesses involved in this study are all locally owned and managed, thus, it is not possible to compare data if the businesses where not locally owned and managed with regards to engaging and contributing to community resilience activities.

Thirdly, there is the need to capture less formal or more ad hoc responses or contributions by businesses to response or recovery that benefit the wider community but may not be organised or accounted for through the formal community resilience mechanisms and structures. Formal responses are, in this context, those actions taken according to local legislations, regulations and standards. Informal response are responses or actions taken by businesses out of good will or a feeling of a sense of community that contribute to enhance businesses and community preparation for and response to emergencies.

Finally, there is also a question of how indicators of business density, characteristics and engagement can be factored into attempts to measure 'community resilience' more broadly. This could be based around the development of a local 'index'-type measure or looking at incorporating business data into existing measures of social vulnerability (Aleksandra Kazmierczak, Gina Cavan, Angela Connelly, \& Sarah Lindley, 2015). By integrating the findings with Cutter et al's (2010) five dimensions of community resilience (social, economic, institutional, infrastructure, and community competence), this analysis suggests that this type of community resilience indicators is useful and seem to capture dimensions of community resilience that is relevant to all groups within the community. However, this does not emphasis the contributions that businesses make on enhancing each of these dimensions. We attempted to do this in this study (see Table 6), however, due to the exploratory nature of this research, a study that draws on larger set of data is required to contribute to the framework in this regards. We suggest that more work is needed in understanding how individual factors - including business resilience - accumulate to shape the different community resilience dimensions proposed by the framework. 


\section{Acknowledgment}

Scottish Funding Council funded this study through the National Centre for Resilience (NCR) (H15037) for Scotland research Centre. The authors declare that there is no conflict of interest. Informed consent was received from all participants in this study. The authors wish to thank Professor Fabrice Renaud for his comments on the draft of this paper.

The views presented in this paper are those of the authors and not of the organizations that the work for. In addition, all errors and omission are those of authors. 


\section{References}

Adekola, J., 2018. Resilience from a lived-experience perspective in the regional context of Dumfries and Galloway, Scotland. International journal of disaster risk reduction, 31, pp.441-448.

Adekola J, Renaud R. \& Hill C (under review). In search of risk and safety information: Difference between gender, age and disabled groups in the use of information sources with regards to a heavy snow storm. Natural Hazards Journal.

Aldrich, D. P., \& Meyer, M. A. (2015). Social capital and community resilience. American Behavioral Scientist, 59(2), 254-269.

Atkinson, C. L. (2013). Toward resilient communities: Examining the impacts of local governments in disasters (Vol. 8): Routledge.

Besser, T., \& Jarnagin, S. (2010). Corporate social responsibility: Small businesses and small towns (History of Corporate Responsibility Project, Working Paper No. 5). Minneapolis, MN: Center for Ethical Business Cultures.

Brown, K. (2014). Global environmental change I: A social turn for resilience? Progress in Human Geography, 38(1), 107-117.

Bryman, A. (2015). Social research methods: Oxford university press.

Clarke, V., \& Braun, V. (2014). Thematic analysis Encyclopedia of critical psychology (pp. 1947-1952): Springer.

Colten, C. E., Kates, R. W., \& Laska, S. B. (2008). Community resilience: Lessons from new orleans and hurricane katrina. CARRI Report, 3.

Crichton, D. (2006). Climate Change and its effects on Small Businesses in the UK

Cutter, S. L., Boruff, B. J., \& Shirley, W. L. (2003). Social vulnerability to environmental hazards. Social science quarterly, 84(2), 242-261.

Davies S and Michie R (2011) Peripheral Regions: A Marginal Concern?, EoRPA Paper 11/06, University of Strathclyde

Doern, R. (2016). Entrepreneurship and crisis management: The experiences of small businesses during the London 2011 riots. International small business journal, 34(3), 276-302.

Hallett, S. (2013). Community Resilience to Extreme Weather-the CREW Project: Final Report. available at: www. exytreme-weather-impacts. net (accessed 20 February 2013). 
Hassink, R. (2010). Regional resilience: a promising concept to explain differences in regional economic adaptability? Cambridge journal of regions, economy and society, 3(1), 45-58.

Herbane, B. (2010). Small business research: Time for a crisis-based view. International small business journal, 28(1), 43-64.

Kapucu, N., \& Sadiq, A.-A. (2016). Disaster Policies and Governance: Promoting Community Resilience.

Kazmierczak, A., Cavan, G., Connelly, A., \& Lindley, S. (2015). Mapping flood disadvantage in Scotland 2015: Scottish Government Edinburgh.

Kazmierczak, A., Cavan, G., Connelly, A., \& Lindley, S. (2015). Mapping Flood Disadvantage in Scotland 2015: Main Report, Scottish Government.

Keane, K. (2017). Rural businesses 'not preparing adequately for Brexit', BBC NEWS. Retrieved from http://www.bbc.co.uk/news/uk-scotland-scotland-business-42165460

Kent, H., \& Fazey, I. (2015). Assessing the Resilience of Organisations Providing Critical Infrastructure Services to Scotland, Scottish Government: Edinburgh.

Leach, K. (2013). Community economic development: Localisation, the key to a resilient and inclusive local economy? Local Economy, 28(7-8), 927-931.

Lekhanya, L. M. (2011). Business characteristics of small and medium enterprises in rural areas: a case study on southern region of KwaZulu-Natal province of South Africa. Management, 14, 3.

MacKinnon, D., \& Derickson, K. D. (2013). From resilience to resourcefulness: A critique of resilience policy and activism. Progress in Human Geography, 37(2), 253-270.

Maybery, D., Pope, R., Hodgins, G., Hitchenor, Y., \& Shepherd, A. (2009). Resilience and well-being of small inland communities: Community assets as key determinants. Rural Society, 19(4), 326-339.

McKnight, B., \& Linnenluecke, M. K. (2016). How firm responses to natural disasters strengthen community resilience: A stakeholder-based perspective. Organization \& Environment, 29(3), 290-307.

Morris, C. (2017, 16 Sept 2017 ). Hurricane alert: 40 percent of small businesses never recover from a disaster, $C N B C$. Retrieved from https://www.cnbc.com/2017/09/16/hurricane-watch-40-percent-of-small-businessesdont-reopen-after-a-disaster.html 
Mowbray, C. T., Woolley, M. E., Grogan-Kaylor, A., Gant, L. M., Gilster, M. E., \& Shanks, T. R. W. (2007). Neighborhood research from a spatially oriented strengths perspective. Journal of Community Psychology, 35(5), 667-680.

Norris, F. H., Stevens, S. P., Pfefferbaum, B., Wyche, K. F., \& Pfefferbaum, R. L. (2008). Community resilience as a metaphor, theory, set of capacities, and strategy for disaster readiness. American journal of community psychology, 41(1-2), 127-150.

Office, C. (2011). Cabinet Office (2011) Preparing for Emergencies: Guide for Communities.

Office, U. C. (2014). Resilience in society: infrastructure, communities and businesses Retrieved from https://www.gov.uk/guidance/resilience-in-society-infrastructurecommunities-and-businesses.

Orhan, E. (2016). Building community resilience: business preparedness lessons in the case of Adapazarı, Turkey. Disasters, 40(1), 45-64.

Palys, T. (2008). Purposive sampling-The sage encyclopedia of qualitative research methods: Vol. 2: Thousand Oaks, CA: Sage Publications Inc.

Paton, D., \& Johnston, D. (2017). Disaster resilience: an integrated approach: Charles C Thomas Publisher.

Pike, A., Dawley, S., \& Tomaney, J. (2010). Resilience, adaptation and adaptability. Cambridge journal of regions, economy and society, 3(1), 59-70.

Preparing Scotland (2016). Preparing Scotland: HAVING AND PROMOTING BUSINESS RESILIENCE.

Programme, U. N. D. (2013). Small Businesses: Impact of Disasters and Building Resilience: Analysing the vulnerability of Micro, Small, and Medium Enterprises to natural hazards and their capacity to act as drivers of community recovery, Background Paper prepared for the Global Assessment Report on Disaster Risk Reduction 2013.

Rogers, C. R. (1981). The foundations of the person-centered approach. Dialectics and Humanism, 8(1), 5-16.

Rosenburg, J. (2017). Past disasters show a long recovery for small businesses The Denver Post. Retrieved from https://www.denverpost.com/2017/09/06/how-hurricanes-affectsmall-businesses/

Scottish Government (2008) Warning and informing Scotland' guidance to communicating with the public in civil emergencies, Edinburgh: Scottish Government

Skerratt, S. (2013). Enhancing the analysis of rural community resilience: evidence from community land ownership. Journal of Rural Studies, 31, 36-46. 
Steiner, A., \& Atterton, J. (2014). The contribution of rural businesses to community resilience. Local Economy, 29(3), 228-244.

Stewart, G. T., Kolluru, R., \& Smith, M. (2009). Leveraging public-private partnerships to improve community resilience in times of disaster. International Journal of Physical Distribution \& Logistics Management, 39(5), 343-364.

Sullivan-Taylor, B., \& Branicki, L. (2011). Creating resilient SMEs: why one size might not fit all. International Journal of Production Research, 49(18), 5565-5579.

Tierney, K. J., \& Webb, G. R. (2001). Business vulnerability to earthquakes and other disasters.

Tilcsik, A., \& Marquis, C. (2013). Punctuated generosity: How mega-events and natural disasters affect corporate philanthropy in US communities. Administrative Science Quarterly, 58(1), 111-148.

Varghese, J., Krogman, N. T., Beckley, T. M., \& Nadeau, S. (2006). Critical analysis of the relationship between local ownership and community resiliency. Rural Sociology, $71(3), 505-527$.

Wedawatta, G., \& Ingirige, B. (2012). Resilience and adaptation of small and medium-sized enterprises to flood risk. Disaster Prevention and Management: An International Journal, 21(4), 474-488.

Woolvin, M., \& Rutherford, A. (2013). Volunteering and public service reform in rural Scotland. SRUC Rural Policy Centre, Edinburgh. 